\title{
Comparison of Conventional and Advanced Echocardiographic Techniques in Early Detection of Cardiotoxicity in Patients Undergoing Cancer Chemotherapy
}

\begin{abstract}
Context: The assessment of left ventricular ejection fraction (LVEF) is the most important component in prediction and detection of cardiotoxicity in patients undergoing cancer chemotherapy. LVEF may not be sensitive enough to pick the cardiotoxicity early since drop in LVEF occurs in the last and irreversible stage. A 10\%-15\% early reduction in global longitudinal strain (GLS) by speckle tracking echocardiography proposed to be the earliest indicator of myocardial dysfunction. Aims: The aim of this study was to compare the early detection of cardiotoxicity (at 0 and 3 months) using drop in LVEF with two-dimensional echocardiography (2DE), three-dimensional echocardiography (3DE), and GLS techniques. Settings and Design: This was a prospective cohort study of patients attending cardiooncology clinic in a tertiary care institute. Subjects and Methods: Newly diagnosed 75 cases of cancer of various etiologies, for whom cardiotoxic chemotherapy drugs has to be used, were included from January 2016 to June 2016. Statistical Analysis Used: Data were analyzed with Pearson's Chi-square test, mean, standard deviation, and 95\% confidence interval. Results: A total of $17(22.6 \%)$ subjects out of 75 , had drop in LVEF by GLS $(<-18.9 \%)$ as compared to $5(6.6 \%)$ in $2 \mathrm{DE}$ and $7(9.3 \%)$ in $3 \mathrm{DE}$ at 3 months with statistically significant $P$ values $(P=0.0001)$. In the 17 subjects who had significant fall in GLS at 3 months, the mean GLS was $-16.17 \pm 1.55 \%$ with a significant reduction of $13.48 \%$ from baseline. Conclusion: Reduction in GLS preceded decrease in ejection fraction. Early detection allows modification of chemotherapeutic regimens and medical intervention preventing the irreversible cardiac damage.
\end{abstract}

Keywords: Cardiotoxicity, chemotherapy, global longitudinal strain, left ventricular ejection fraction, speckle tracking echocardiography

\section{Introduction}

The estimated cancer mortality has decreased worldwide over the past 20-30 years. ${ }^{[1,2]}$ However, cardiotoxicity from cancer chemotherapy has become a leading cause of morbidity and mortality in cancer survivors. ${ }^{[3,4]}$ Cardiac dysfunction resulting from exposure to cancer chemotherapeutics was first recognized in the 1960 s, with the widespread introduction of anthracyclines. ${ }^{[5]}$ The mortality rate is as high as $60 \%$ by 2 years for patients who develop heart failure (HF) from cancer chemotherapy. ${ }^{[6]}$ Hence, careful consideration of potential cardiotoxicity during chemotherapy is necessary, with a focus on early detection and intervention. ${ }^{[7]}$

Several criteria have been proposed to define cardiotoxicity. ${ }^{[8]}$ According to Cardiac Review and Evaluation Committee,

This is an open access journal, and articles are distributed under the terms of the Creative Commons Attribution-NonCommercial-ShareAlike 4.0 License, which allows others to remix, tweak, and build upon the work non-commercially, as long as appropriate credit is given and the new creations are licensed under the identical terms.

For reprints contact: reprints@medknow.com cardiotoxicity is most commonly defined as $\geq 10 \%$ reduction in asymptomatic patients (or $\geq 5 \%$ reduction in symptomatic patients) in the left ventricular ejection fraction (LVEF) from baseline to an LVEF $<55 \%$. ${ }^{[9]}$

Modern chemotherapy agents direct against several molecular targets such as antiepidermal growth factor receptor (EGFR) signaling including antihuman epidermal growth factor receptor 2 (HER2), anti-EGFR1, antivascular endothelial growth factor (VEGF), antimammalian target of rapamycin, tyrosine kinase inhibitors, and antimesenchymal-epithelial transition. ${ }^{[10]}$

Antineoplastic drugs causing cancer therapeutics-related cardiac dysfunction (CTRCD) can be classified into Type I and Type II agents. Type I CTRCD is caused by anthracyclines (doxorubicin),

How to cite this article: Pradeep HN,
Rupesh G, Anil TJ, Geethu K, Jayakumar TG,
Abdul SK. Comparison of conventionaland advanced
echocardiographic techniques in early detection
of cardiotoxicity in patients undergoing cancer
chemotherapy. Indian J Med Paediatr Oncol
2018;39:429-35.

How to cite this article: Pradeep HN, Rupesh G, Anil TJ, Geethu K, Jayakumar TG, Abdul SK. Comparison of conventional and advanced echocardiographic techniques in early detection chemotherapy. Indian J Med Paediatr Oncol 2018;39:429-35.

\section{HN Pradeep, George Rupesh, Thazhath J Anil', Krishnan Geethu, TG Jayakumar, S Khadar Abdul}

Departments of Cardiology and ${ }^{1}$ Medical Oncology, Amala Institute of Medical Sciences, Thrissur, Kerala, India

\author{
Address for correspondence: \\ Dr. HN Pradeep, \\ Department of Cardiology, \\ Amala Institute of Medical \\ Sciences, Amala Nagar, \\ Thrissur - 680 555, Kerala, \\ India. \\ E-mail: saipradeepvivek@gmail. \\ com
}

Access this article online

Website: www.ijmpo.org

DOI: 10.4103/ijmpo.ijmpo_114_17

Quick Response Code:

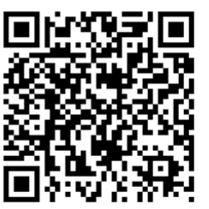


nonanthracyclines, and alkylating agents where dose-dependent irreversible cardiac dysfunction occurs due to generation of reactive oxygen species (ROS). It is mediated by topoisomerase-II $\beta$ in cardiomyocytes through the formation of ternary complexes (topoisomerase-II $\beta$-ant hracycline-deoxyribonucleic acid). These complexes induce deoxyribonucleic acid double-strand breaks and transcriptome changes responsible for defective mitochondrial biogenesis and ROS formation. ${ }^{[11]}$ Electron microscopy of myocardial biopsies shows varying degrees of myocyte damage, vacuolar swelling progressing to myofibrillar disarray, and ultimately cell death. ${ }^{[12]}$ These agents are now considered to have increased potential for long-term cardiac dysfunction and increased morbidity and mortality. ${ }^{[13,14]}$

Type II CTRCD is caused by HER2 inhibitors (trastuzumab) and VEGF inhibitors where dose-independent reversible cardiac dysfunction occurs. These agents do not directly cause cell damage in a cumulative dose-dependent fashion. Combined anticancer therapy with Class I and II agents is associated with a higher than expected incidence of cardiac dysfunction. ${ }^{[15]}$

Echocardiography is the cornerstone in the cardiac imaging evaluation of patients during and after cancer therapy because of its wide availability, easy repeatability, versatility, lack of radiation exposure, and safety in patients with renal disease. It can be used for evaluation of left ventricle (LV), right ventricle dimensions, and systolic and diastolic function. ${ }^{[16]}$

Potential exposure to cardiotoxic chemotherapeutic agents is a well-recognized indication for baseline and longitudinal evaluation of LV function. The most commonly used parameter for monitoring LV function with echocardiography is LVEF. $^{[17,18]}$

Historically, fractional shortening using linear measurements from M-mode echocardiography or two-dimensional echocardiography (2DE) was used as a surrogate marker of LVEF in the evaluation of oncological patients. The method of choice for LVEF calculation is the modified biplane Simpson's technique (method of disks) by $2 \mathrm{DE}$ as recommended by American Society of Echocardiography (ASE) and European Association of Echocardiography (EAE). ${ }^{[19]}$ The normal reference range for LVEF as recommended by ASE and EAE is $\geq 55 \%$. LVEF in the range of $53 \%-73 \%$ should be classified as normal. ${ }^{[20]}$ Different methods of LVEF measurements are used in various studies such as Teichholz, Simpson's biplane, and area-length method. ${ }^{[21]}$

LVEF calculated by conventional $2 \mathrm{DE}$ often fails to detect small changes in LV contractility because of factors such as LV geometric assumptions, inadequate visualization of the true $\mathrm{LV}$ apex, lack of consideration of subtle wall motion abnormalities, and inherent variability of the measurement. ${ }^{[22]} \mathrm{LVEF}$ has low sensitivity for the detection of small changes in LV function. 2DE appears to be reliable in the detection of differences close to $10 \%$ in LVEF. ${ }^{[23]}$

The use of LVEF has important limitations such as technique-related variability, which can be higher than the thresholds used to define cardiotoxicity. ${ }^{[24]}$ Furthermore, the reduction in LVEF is often a late phenomenon, with failure to recover systolic function in up to $58 \%$ of patients despite intervention. ${ }^{[25]}$

Hence, strategies using newer echocardiographic techniques such as three-dimensional echocardiography (3DE) and speckle tracking echocardiography (STE)-derived global longitudinal strain (GLS) imaging is used for the early detection of subclinical LV systolic dysfunction. ${ }^{[26]}$

$3 \mathrm{DE}$ is more accurate than $2 \mathrm{DE}$ for the measurement of LV volumes with improved accuracy (sensitivity - 53\%; false negative rate - 47\%) when compared to 2DE (sensitivity - 25\%; false negative rate - 75\%). ${ }^{[27]} 3 \mathrm{DE}$ volume measurements are not conditioned by errors induced by geometric assumptions of LV shape, foreshortening of views, or uncontrolled orientation of apical two-chamber and four-chamber views that commonly affect the accuracy of $2 \mathrm{DE}$. 3DE appears to be the technique of choice for monitoring the cardiac effects of chemotherapy. ${ }^{[28]}$

Markers of early myocardial changes with normal LVEF like the myocardial deformation indices (strain, strain rate [SR], and twist) are used for earlier detection of subclinical LV dysfunction in patients treated for cancer. Myocardial deformation can be measured during routine echocardiography, and its prognostic value has been demonstrated in several clinical trials. ${ }^{[29]}$

Strain is a dimensionless index reflecting the total deformation of the ventricular myocardium during a cardiac cycle as a percentage of its initial length (reported as percentage). ${ }^{[30]}$ Negative strain implies shortening of a segment and positive strain as lengthening of a segment. ${ }^{[31]}$ SR is the rate of deformation or stretch. ${ }^{[32]}$ Both strain and SR can be measured in the longitudinal, radial, and circumferential directions. ${ }^{[29,32]}$ A key advantage of strain or SR measurement is its ability to differentiate active versus passive movement within a myocardial segment, allowing for the analysis of regional myocardial deformation independent of the translational motion of the heart. ${ }^{[30]}$

The decrease in myocardial systolic function induced by anthracyclines appears to be extremely rapid as early as $2 \mathrm{~h}$ after the first anthracycline dose. ${ }^{[33]}$ The decrease in myocardial deformation indices preceded the decrease in LVEF and persisted during the subsequent cancer chemotherapy. Early decrease in radial and longitudinal strain using STE has been confirmed with subjects treated with anthracyclines, with or without later decrease in LVEF. $^{[34]}$ 
Normal ranges for GLS are defined as mean GLS of $-19.7 \%$ and $95 \%$ confidence interval of $-20.4 \%$ to $-18.9 \%{ }^{[35]}$ An early fall in GLS by STE between $10 \%$ and $15 \%$ predicts subsequent cardiotoxicity in both asymptomatic and symptomatic LV dysfunction patients. ${ }^{[34,36]}$ This change in GLS between $10 \%$ and $15 \%$ appears to have the best specificity for predicting future cardiotoxicity. ${ }^{[30,35]}$ The $95 \%$ confidence interval for the optimal GLS cutoff extends from $8.3 \%$ to $14.6 \%{ }^{[36]}$ Tarr et al. believed that detecting myocardial dysfunction by GLS requires $>3$ months of follow-up. ${ }^{[37]}$

\section{Subjects and Methods}

This was a prospective cohort study of 75 subjects who were newly diagnosed with cancer of various etiologies and planned for cancer chemotherapy from January 2016 to June 2016 were included, after obtaining approval from the Institutional Ethical Committee. Subjects included were those attending the cardiooncology clinic of our hospital. Baseline 0 month and at the end of 3 months, 2DE, 3DE, and GLS were compared. GLS are measured in standard apical two-, three-, and four-chamber views and aortic valve closure is used for timing of end systole [Figure 1]. The same vendor (Philips EPIQ 7C) echocardiography was used for all measurements.

Informed consent was taken from the subjects before being admitted to the study. A detailed clinical examination, including vital parameters and anthropometry, was taken.

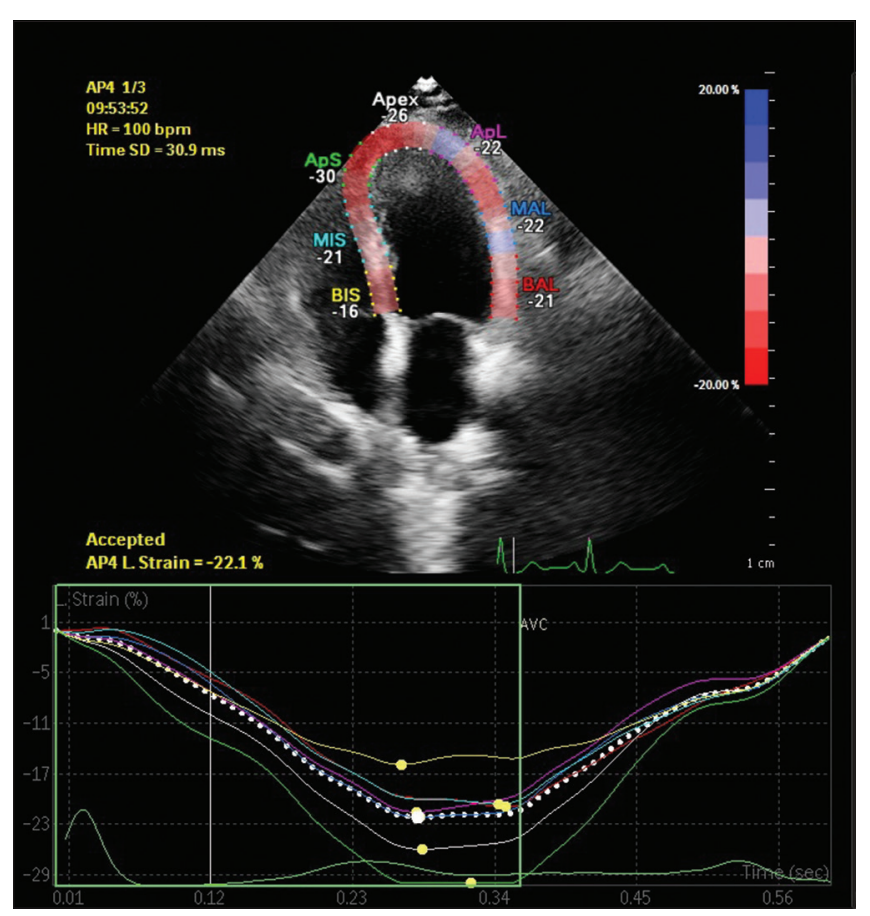

Figure 1: Speckle tracking echocardiography illustrating global longitudinal strain from the apical long-axis four-chamber-view, showing normal left ventricular segmental strain pattern. The color of each trace corresponds to anatomical points on the two-dimensional color image above. The white-dotted line represents average strain
The chemotherapy regimen, route, and dose of drugs were decided by the treating medical oncologist.

The most commonly used chemotherapy combination was intravenous three cycles of FAC (5 fluorouracil, adriamycin/doxorubicin, cyclophosphamide) and D (docetaxel). The chemotherapeutic doses were adjusted according to body weight and are as follows: 5 fluorouracil $-500 \mathrm{mg} / \mathrm{m}^{2}$, doxorubicin - $50 \mathrm{mg} / \mathrm{m}^{2}$, cyclophosphamide - $500 \mathrm{mg} / \mathrm{m}^{2}$, and docetaxel - 90-100 mg/m².

Data were analyzed using Pearson's Chi-square test, mean, standard deviation, and 95\% confidence interval. Demographic variables in categories were given in frequencies with their percentages. IBM SPSS Statistics 23 software, IBM Corporation, New York, United States was used to analyze the statistics. $P<0.05$ was considered statistically significant.

\section{Results}

The mean age of the study population was $55.36( \pm 9.92)$ years. Of total 75 patients, 55 were female $(73.3 \%)$ and 20 were male $(26.7 \%)$. Most common cancer in the study population was breast cancer ( $n=42,56 \%)$, followed by non-Hodgkin's lymphoma ( $n=11,14.6 \%$ ) [Bar Graph 1]. The most common chemotherapeutic agent used was intravenous FAC $\times 3$ (5 fluorouracil, adriamycin/doxorubicin, cyclophosphamide) followed by $\mathrm{D} \times 3$ (docetaxel).

Of 75 subjects, $17(22.6 \%)$ had a significant reduction in early myocardial deformation indices as measured by two-dimensional (2D) STE using GLS at the end of 3 months chemotherapy (GLS <-18.9\%), when compared to 5 subjects $(6.6 \%)$ who had decrease in LVEF $(\leq 53 \%)$ in 2 DE. The above $P$ value was statistically significant $(P=0.0001)$ with sensitivity of $29 \%$, specificity of $100 \%$, positive predictive value (PPV) of $100 \%$, and negative predictive value (NPV) of $82.8 \%$. At 0 month, 6 subjects $(8 \%)$ of GLS and 1 subject $(1.3 \%)$ of $2 \mathrm{DE}$ had drop in LVEF from the normal baseline values.

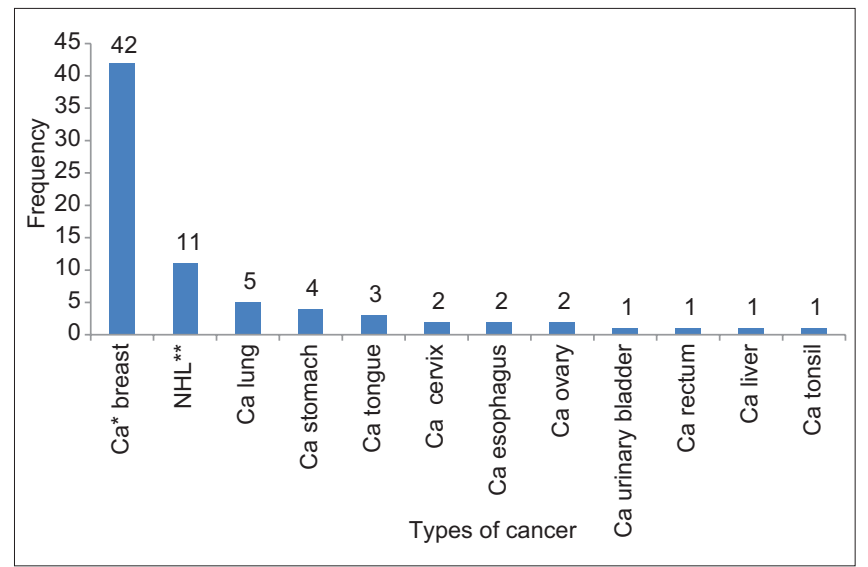

Bar Graph 1: Types of cancer $\left({ }^{*} \mathrm{Ca}-\right.$ Carcinoma; ${ }^{* *} \mathrm{NHL}-$ Non-Hodgkin's lymphoma) 
Furthermore, GLS as compared with 3DE had a significant reduction in GLS in $17(22.6 \%)$ subjects when compared to $7(9.3 \%)$ subjects in $3 \mathrm{DE}$. The above $P$ value was statistically significant $(P=0.0001)$, with sensitivity of $41.8 \%$, specificity of $100 \%$, PPV of $100 \%$, and NPV of $85.2 \%$. At 0 month, 6 subjects $(8 \%)$ of GLS and 4 subjects $(5.3 \%)$ of 3DE had drop in LVEF from the normal baseline values.

Of 17 subjects who had a significant reduction in GLS at the end of 3 month cancer chemotherapy, 11 subjects (64.7\%) had received anthracycline-based chemotherapy.

The mean GLS at the end of 3 months' chemotherapy in the total 75 subjects was $-20.60 \pm 3.22 \%$ when compared to the baseline 0 month GLS of $-22.41 \pm 2.96 \%$ [Table 1]. There was a reduction of $8.07 \%$ GLS from the baseline. In the 17 subjects who had a significant fall in GLS at 3 months, the mean GLS was $-16.17 \pm 1.55 \%$ when compared to the 0 -month GLS of $-18.69 \pm 2.25$ with a significant reduction of $13.48 \%$ from baseline [Table 2]. A "bull's eye" plot of strain values for each of the 17 myocardial segments gives better reproducibility and higher availability for detection of early cardiotoxicity [Figure 2].

There was a significant effect of gender on GLS with lower values seen in males when compared to female subjects at both baseline and 3 months. Mean GLS at 3 months for males and females was $-18.57 \pm 3.52 \%$ and $-21.28 \pm$ $2.86 \%$, respectively [Tables 3 and 4 ].

The cardiotoxicity rate detected by GLS at 3 months was $22.66 \%$ when compared $9.3 \%$ with $3 \mathrm{DE}$ and $6.6 \%$ with 2DE.

\section{Discussion}

The mean age of study population was $55.36 \pm 9.9$ years which were comparable with other studies using advanced myocardial mechanics such as strain imaging to study

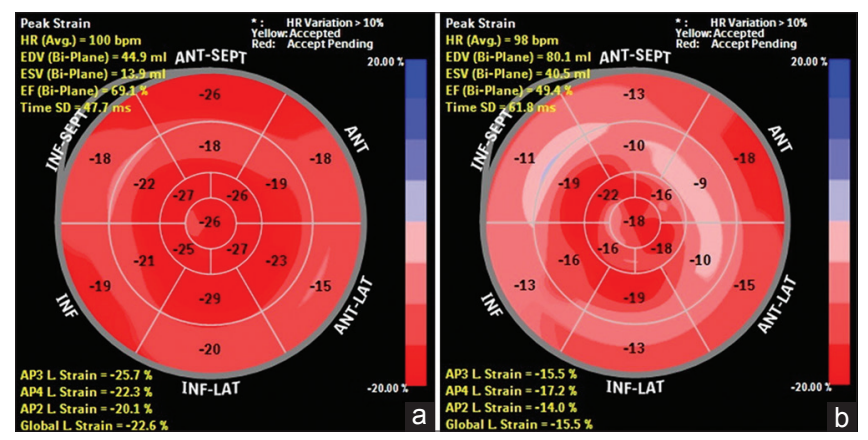

Figure 2: (a) Prechemotherapy bull's eye plot in our patient showing global longitudinal strain values of the 17 myocardial segments with baseline global longitudinal strain of $\mathbf{- 2 2 . 6 \%}$, three-dimensional left ventricular ejection fraction of $66 \%$, and two-dimensional left ventricular ejection fraction of $60 \%$. (b) Three months following chemotherapy in the same patient bull's eye plot showed global longitudinal strain of $-15.5 \%$ (global longitudinal strain fell by $31.4 \%$, indicating significant cardiotoxicity), three-dimensional left ventricular ejection fraction of $50 \%$, and two-dimensional left ventricular ejection fraction of $\mathbf{5 5 \%}$ (two-dimensional left ventricular ejection fraction fell by $5 \%$ and not significant) cancer chemotherapy. The studies of Motoki et al., Cadeddu et al., and Mantovani et al. had mean age group of $58 \pm 11,56 \pm 13$, and $59 \pm 14$ years, respectively. ${ }^{[38-40]}$ The percentage of women in the study population was $73.3 \%$ which was comparable with studies of Cadeddu et al. and Mantovani et al., where the percentages were $76 \%$ and $74 \%$, respectively. ${ }^{[39,40]}$

The most common cancer chemotherapeutic agent used was anthracycline analogs such as adriamycin (doxorubicin) in 49 subjects $(65.3 \%)$ of the total 75 subjects, followed by

Table 1: Comparison between 0-month and 3-month

two-dimensional left ventricular ejection fraction, three-dimensional left ventricular ejection fraction, and global longitudinal strain

\begin{tabular}{lccc}
\hline & $\begin{array}{c}\text { 2D mean } \pm \text { 2SD } \\
\mathbf{( \% )}\end{array}$ & $\begin{array}{c}\text { 3D mean } \pm \text { 2SD } \\
\mathbf{( \% )}\end{array}$ & $\begin{array}{c}\text { GLS mean } \pm \text { 2SD } \\
(\mathbf{\% )}\end{array}$ \\
\hline 0 month & $67.49 \pm 5.43$ & $58.85 \pm 7.23$ & $-22.41 \pm 2.96$ \\
3 month & $62.41 \pm 7.60$ & $54.93 \pm 6.44$ & $-20.60 \pm 3.22$ \\
\hline
\end{tabular}

2D - Two-dimensional; 3D - Three-dimensional; GLS - Global

longitudinal strain; SD - Standard deviation

Table 2: Percentage reduction in global longitudinal strain at 3 months when compared to 0 month

\begin{tabular}{lccc}
\hline $\begin{array}{l}\text { Significant } \\
\text { GLS fall }\end{array}$ & \multicolumn{2}{c}{ Mean \pm 2SD } & $\begin{array}{c}\text { Percentage } \\
\text { reduction }\end{array}$ \\
\cline { 2 - 3 } & $\begin{array}{c}\mathbf{0} \text { month GLS } \\
\mathbf{( \% )}\end{array}$ & $\begin{array}{c}\text { 3 month GLS } \\
\mathbf{( \% )}\end{array}$ & \\
\hline Yes $(n=17)$ & $-18.69 \pm 2.25$ & $-16.17 \pm 1.55$ & 13.48 \\
No $(n=58)$ & $-23.51 \pm 2.08$ & $-21.90 \pm 2.28$ & 6.84 \\
Total $(n=75)$ & $-22.41 \pm 2.96$ & $-20.60 \pm 3.22$ & 8.07 \\
\hline
\end{tabular}

GLS - Global longitudinal strain; SD - Standard deviation

Table 3: Comparison between 0-month two-dimensional left ventricular ejection fraction, three-dimensional left ventricular ejection fraction, and global longitudinal strain

\begin{tabular}{lccc}
\hline & $\begin{array}{c}\text { 2D mean } \pm \text { 2SD } \\
(\mathbf{\% )}\end{array}$ & $\begin{array}{c}\text { 3D mean } \pm \text { 2SD } \\
\mathbf{( \% )}\end{array}$ & $\begin{array}{c}\text { GLS mean } \pm \mathbf{2 S D} \\
\mathbf{( \% )}\end{array}$ \\
\hline Female & $68.52 \pm 4.58$ & $60.25 \pm 6.24$ & $-23.18 \pm 2.50$ \\
Male & $64.65 \pm 6.92$ & $54.95 \pm 8.43$ & $-20.3 \pm 3.14$ \\
Total & $67.49 \pm 5.43$ & $58.85 \pm 7.23$ & $-22.41 \pm 2.96$ \\
\hline
\end{tabular}

GLSL - Global longitudinal strain; SD - Standard deviation; 2D - Two-dimensional; 3D - Three-dimensional

Table 4: Comparison between 3-month two-dimensional, left ventricular ejection fraction, three-dimensional left ventricular ejection fraction, and global longitudinal strain

\begin{tabular}{lccc}
\hline & $\begin{array}{c}\text { 2D mean } \pm \text { 2SD } \\
\mathbf{( \% )}\end{array}$ & $\begin{array}{c}\text { 3D mean } \pm \text { 2SD } \\
\mathbf{( \% )}\end{array}$ & $\begin{array}{c}\text { GLS mean } \pm \mathbf{2 S D} \\
\mathbf{( \% )}\end{array}$ \\
\hline Female & $63.63 \pm 6.87$ & $56.23 \pm 5.79$ & $-21.28 \pm 2.86$ \\
Male & $59.05 \pm 8.64$ & $51.35 \pm 6.93$ & $-18.57 \pm 3.52$ \\
Total & $62.41 \pm 7.60$ & $54.93 \pm 6.44$ & $-20.57 \pm 3.26$ \\
\hline 2D - Two-dimensional; 3D - Three-dimensional; GLS - Global \\
longitudinal strain; SD - Standard deviation
\end{tabular}


epirubicin in $6(8 \%)$ subjects and the HER 2 monoclonal antibody, trastuzumab in $5(6.6 \%)$ subjects, respectively. Furthermore, the study of cancer chemotherapy done by Baratta et al. had doxorubicin in 58\% and trastuzumab in $22 \%$ subjects. ${ }^{[41]}$ Another study done by Stoodley et al. had doxorubicin in $77 \%$ and epirubicin in $23 \%$ subjects. ${ }^{[42]}$

The pre- and post-chemotherapy GLS at 0 month and 3 months were $-22.41 \pm 2.96 \%$ and $-20.60 \pm 3.22 \%$, respectively. Similarly, studies done by Baratta et al. and Sawaya et al. had pre- and post-chemotherapy GLS at 0 month $(-20.3 \pm 2.7 \%,-21 \pm 2 \%)$ and 3 months $(-18.9 \pm 2.5 \%,-19.2 \pm 2 \%)$, respectively. ${ }^{[41,43]}$

The percentage reduction of GLS was $8.07 \%$ from baseline at 3 months in the total 75 study subjects. While the percentage reduction was $13.48 \%$ in 17 subjects $(22.6 \%)$ who had a significant reduction in GLS at 3 months when compared to the baseline. Negishi et al. have proposed the strongest predictor of CTRCD was GLS at 6 months. An $11 \%$ reduction of GLS was the optimal cutoff, with sensitivity of $65 \%$, specificity of $94 \%$, and $95 \%$ confidence interval of $8.3 \%-14.6 \%$, respectively. In the same study, it was concluded that reduction of GLS $<8 \%$ compared with the baseline appears not to be clinically meaningful, whereas $>15 \%$ reduction appears to be of clinical significance. ${ }^{[36]}$ Reductions in myocardial deformation parameters such as GLS are a sign of subclinical myocardial changes from cancer therapy and occur before any change in LVEF as assessed by conventional 2DE. ${ }^{[30]}$

The cardiotoxicity rate was $22.66 \%$ which was seen in 17 subjects by GLS method at 3 months following chemotherapy. Similarly, the cardiotoxicity rate was $19.4 \%$ and $21 \%$ in the studies conducted by Baratta et al. and Sawaya et al., respectively. ${ }^{[41,43]}$

The mean normal GLS at baseline was lower in men when compared to women with values being $-20.3 \pm 3.14 \%$ and $-23.18 \pm 2.50 \%$, respectively. The study of Kocabay et al. reported a mean GLS of $-20.7 \pm 2 \%$ for men and $-22.1 \pm 1.8 \%$ for women, respectively. ${ }^{[4]}$ These values were comparable with our study results. Furthermore, the Japanese Ultrasound Speckle Tracking of the Left Ventricle study showed lower GLS values for men when compared to women. ${ }^{[45]}$

Limitations of the study include the small sample size and shorter follow-up period. The 2D LVEF was measured by Teichholz method while the recommended method was Simpson's method which could have still predicted better drop in LVEF. Biomarkers such as troponins and N-terminal pro brain type natriuretic peptide which could detect subclincal LV dysfunction was not used in our study.

\section{Conclusion}

Myocardial deformation indices such as GLS are the optimal parameter to be used for early detection of subclinical LV dysfunction in cancer chemotherapy subjects. GLS is favored because of a lack of angle dependency and better reproducibility. The GLS measurements during chemotherapy should be compared with the baseline value. A relative percentage reduction of GLS $>15 \%$ from the baseline is very likely to be abnormal and predicts subsequent cardiotoxicity including asymptomatic and symptomatic LV dysfunction. Early detection of decline in GLS helps subjects to be benefitted from cardioprotective therapy and modification of chemotherapeutic regimen.

\section{Acknowledgment}

We thank the colleagues at the Department of Cardiology and Medical Oncology for their valuable support. We are grateful to Mr. Vidhu M Joshy for his advice on statistical analysis.

\section{Financial support and sponsorship}

Nil.

\section{Conflicts of interest}

There are no conflicts of interest.

\section{References}

1. Coleman MP, Forman D, Bryant H, Butler J, Rachet B, Maringe C, et al. Cancer survival in Australia, Canada, Denmark, Norway, Sweden, and the UK, 1995-2007 (the International Cancer Benchmarking Partnership): An analysis of population-based cancer registry data. Lancet 2011;377:127-38.

2. International Agency for Research on Cancer. World Cancer Fact Sheet. Geneva, Switzerland: World Health Organization; 2012. Available from: http://www.gicr.iarc.fr/files/ resources/20120906-WorldCancerFactSheet.pdf. [Last accessed on 2013 Sep 01].

3. Hooning MJ, Botma A, Aleman BM, Baaijens MH, Bartelink H, Klijn JG, et al. Long-term risk of cardiovascular disease in 10-year survivors of breast cancer. J Natl Cancer Inst 2007;99:365-75.

4. Doyle JJ, Neugut AI, Jacobson JS, Grann VR, Hershman DL. Chemotherapy and cardiotoxicity in older breast cancer patients: A population-based study. J Clin Oncol 2005;23:8597-605.

5. Tan C, Tasaka H, Yu KP, Murphy ML, Karnofsky DA. Daunomycin, an antitumor antibiotic, in the treatment of neoplastic disease. Clinical evaluation with special reference to childhood leukemia. Cancer 1967;20:333-53.

6. Felker GM, Thompson RE, Hare JM, Hruban RH, Clemetson DE, Howard DL, et al. Underlying causes and long-term survival in patients with initially unexplained cardiomyopathy. N Engl J Med 2000;342:1077-84.

7. Negishi K, Negishi T, Haluska BA, Hare JL, Plana JC, Marwick TH, et al. Use of speckle strain to assess left ventricular responses to cardiotoxic chemotherapy and cardioprotection. Eur Heart J Cardiovasc Imaging 2014;15:324-31.

8. Khouri MG, Douglas PS, Mackey JR, Martin M, Scott JM, Scherrer-Crosbie $\mathrm{M}$, et al. Cancer therapy-induced cardiac toxicity in early breast cancer: Addressing the unresolved issues. Circulation 2012;126:2749-63.

9. Martín M, Esteva FJ, Alba E, Khandheria B, Pérez-Isla L, García-Sáenz JA, et al. Minimizing cardiotoxicity while 
optimizing treatment efficacy with trastuzumab: Review and expert recommendations. Oncologist 2009;14:1-11.

10. Yuan DD, Zhu ZX, Zhang X, Liu J. Targeted therapy for gastric cancer: Current status and future directions (Review). Oncol Rep 2016;35:1245-54.

11. Zhang S, Liu X, Bawa-Khalfe T, Lu LS, Lyu YL, Liu LF, et al. Identification of the molecular basis of doxorubicin-induced cardiotoxicity. Nat Med 2012;18:1639-42.

12. Friedman MA, Bozdech MJ, Billingham ME, Rider AK. Doxorubicin cardiotoxicity. serial endomyocardial biopsies and systolic time intervals. JAMA 1978;240:1603-6.

13. Ewer MS, Lippman SM. Type II chemotherapy-related cardiac dysfunction: Time to recognize a new entity. J Clin Oncol 2005;23:2900-2.

14. Suter TM, Ewer MS. Cancer drugs and the heart: Importance and management. Eur Heart J 2013;34:1102-11.

15. Slamon DJ, Leyland-Jones B, Shak S, Fuchs H, Paton V, Bajamonde A, et al. Use of chemotherapy plus a monoclonal antibody against HER2 for metastatic breast cancer that overexpresses HER2. N Engl J Med 2001;344:783-92.

16. Daher IN, Kim C, Saleh RR, Plana JC, Yusuf SW, Banchs J, et al. Prevalence of abnormal echocardiographic findings in cancer patients: A retrospective evaluation of echocardiography for identifying cardiac abnormalities in cancer patients. Echocardiography 2011;28:1061-7.

17. Cheitlin MD, Armstrong WF, Aurigemma GP, Beller GA, Bierman FZ, Davis JL, et al. ACC/AHA/ASE 2003 guideline update for the clinical application of echocardiography: Summary article. A report of the American College of Cardiology/American Heart Association task force on practice guidelines (ACC/AHA/ ASE committee to update the 1997 guidelines for the clinical application of echocardiography). J Am Soc Echocardiogr 2003;16:1091-110.

18. American College of Cardiology Foundation Appropriate Use Criteria Task Force. American Society of Echocardiography. American Heart Association. American Society of Nuclear Cardiology. Heart Failure Society of America. Heart Rhythm Society. et al. ACCF/ASE/AHA/ASNC/HFSA/HRS/SCAI/ SCCM/SCCT/SCMR 2011 appropriate use criteria for echocardiography. A report of the American College of Cardiology foundation appropriate use criteria task force, American Society of Echocardiography, American heart association, American society of nuclear cardiology, heart failure society of America, heart rhythm society, society for cardiovascular angiography and interventions, society of critical care medicine, society of cardiovascular computed tomography, society for cardiovascular magnetic resonance American college of chest physicians. J Am Soc Echocardiogr 2011;24:229-67.

19. Lang RM, Bierig M, Devereux RB, Flachskampf FA, Foster E, Pellikka PA, et al. Recommendations for chamber quantification: A report from the American Society of Echocardiography's guidelines and standards committee and the chamber quantification writing group, developed in conjunction with the European Association of Echocardiography, a branch of the European Society of Cardiology. J Am Soc Echocardiogr 2005; 18:1440-63.

20. Lancellotti P, Badano LP, Lang RM, Akhaladze N, Athanassopoulos GD, Barone $\mathrm{D}$, et al. Normal reference ranges for echocardiography: Rationale, study design, and methodology (NORRE study). Eur Heart J Cardiovasc Imaging 2013;14:303-8.

21. Seidman A, Hudis C, Pierri MK, Shak S, Paton V, Ashby M, et al. Cardiac dysfunction in the trastuzumab clinical trials experience. J Clin Oncol 2002;20:1215-21.
22. Jacobs LD, Salgo IS, Goonewardena S, Weinert L, Coon P, Bardo $\mathrm{D}$, et al. Rapid online quantification of left ventricular volume from real-time three-dimensional echocardiographic data. Eur Heart J 2006;27:460-8.

23. Otterstad JE, Froeland G, St John Sutton M, Holme I. Accuracy and reproducibility of biplane two-dimensional echocardiographic measurements of left ventricular dimensions and function. Eur Heart J 1997;18:507-13.

24. Thavendiranathan P, Grant AD, Negishi T, Plana JC, Popović ZB, Marwick TH, et al. Reproducibility of echocardiographic techniques for sequential assessment of left ventricular ejection fraction and volumes: Application to patients undergoing cancer chemotherapy. J Am Coll Cardiol 2013;61:77-84.

25. Cardinale D, Colombo A, Lamantia G, Colombo N, Civelli M, De Giacomi G, et al. Anthracycline-induced cardiomyopathy: Clinical relevance and response to pharmacologic therapy. J Am Coll Cardiol 2010;55:213-20.

26. Plana JC, Galderisi M, Barac A, Ewer MS, Ky B, Scherrer-Crosbie M, et al. Expert consensus for multimodality imaging evaluation of adult patients during and after cancer therapy: A report from the American Society of Echocardiography and the European Association of Cardiovascular Imaging. Eur Heart J Cardiovasc Imaging 2014;15:1063-93.

27. Armstrong GT, Plana JC, Zhang N, Srivastava D, Green DM, Ness KK, et al. Screening adult survivors of childhood cancer for cardiomyopathy: Comparison of echocardiography and cardiac magnetic resonance imaging. J Clin Oncol 2012;30:2876-84.

28. Mor-Avi V, Lang RM. Is echocardiography reliable for monitoring the adverse cardiac effects of chemotherapy? J Am Coll Cardiol 2013;61:85-7.

29. Geyer H, Caracciolo G, Abe H, Wilansky S, Carerj S, Gentile F, et al. Assessment of myocardial mechanics using speckle tracking echocardiography: Fundamentals and clinical applications. J Am Soc Echocardiogr 2010;23:351-69.

30. Thavendiranathan P, Poulin F, Lim KD, Plana JC, Woo A, Marwick TH, et al. Use of myocardial strain imaging by echocardiography for the early detection of cardiotoxicity in patients during and after cancer chemotherapy: A systematic review. J Am Coll Cardiol 2014;63:2751-68.

31. Armstrong WF, Ryan T. Evaluation of systolic function of the left ventricle. Feigenbaum's Echocardiography. $7^{\text {th }}$ ed. Wolters Kluwer (India) Pvt.Ltd., New Delhi: Lippincott Williams \& Wilkins; 2011. p. 123-58.

32. Mor-Avi V, Lang RM, Badano LP, Belohlavek M, Cardim NM, Derumeaux G, et al. Current and evolving echocardiographic techniques for the quantitative evaluation of cardiac mechanics: ASE/EAE consensus statement on methodology and indications endorsed by the Japanese society of echocardiography. Eur J Echocardiogr 2011;12:167-205.

33. Ganame J, Claus P, Eyskens B, Uyttebroeck A, Renard M, D'hooge $\mathrm{J}$, et al. Acute cardiac functional and morphological changes after anthracycline infusions in children. Am J Cardiol 2007;99:974-7.

34. Sawaya H, Sebag IA, Plana JC, Januzzi JL, Ky B, Cohen V, et al. Early detection and prediction of cardiotoxicity in chemotherapy-treated patients. Am J Cardiol 2011;107:1375-80.

35. Yingchoncharoen T, Agarwal S, Popović ZB, Marwick TH. Normal ranges of left ventricular strain: A meta-analysis. J Am Soc Echocardiogr 2013;26:185-91.

36. Negishi K, Negishi T, Hare JL, Haluska BA, Plana JC, Marwick TH, et al. Independent and incremental value of deformation indices for prediction of trastuzumab-induced cardiotoxicity. J Am Soc Echocardiogr 2013;26:493-8. 
37. Tarr A, Stoebe S, Tuennemann J, Baka Z, Pfeiffer D, Varga A, et al. Early detection of cardiotoxicity by $2 \mathrm{D}$ and $3 \mathrm{D}$ deformation imaging in patients receiving chemotherapy. Echo Res Pract 2015;2:81-8.

38. Motoki H, Koyama J, Nakazawa H, Aizawa K, Kasai H, Izawa A, et al. Torsion analysis in the early detection of anthracycline-mediated cardiomyopathy. Eur Heart J Cardiovasc Imaging 2012;13:95-103.

39. Cadeddu C, Piras A, Mantovani G, Deidda M, Dessì M, Madeddu C, et al. Protective effects of the angiotensin II receptor blocker telmisartan on epirubicin-induced inflammation, oxidative stress, and early ventricular impairment. Am Heart J 2010;160:487.e1-7.

40. Mantovani G, Madeddu C, Cadeddu C, Dessì M, Piras A, Massa E, et al. Persistence, up to 18 months of follow-up, of epirubicin-induced myocardial dysfunction detected early by serial tissue Doppler echocardiography: Correlation with inflammatory and oxidative stress markers. Oncologist 2008;13:1296-305.

41. Baratta S, Damiano M, Marchese M, Trucco J, Rizzo M, Bernok F, et al. Serum markers, conventional Doppler echocardiography and two-dimensional systolic strain in the diagnosis of chemotherapy-induced myocardial toxicity. Rev Argent Cardiol 2013;81:151-8.

42. Stoodley PW, Richards DA, Boyd A, Hui R, Harnett PR, Meikle SR, et al. Altered left ventricular longitudinal diastolic function correlates with reduced systolic function immediately after anthracycline chemotherapy. Eur Heart J Cardiovasc Imaging 2013;14:228-34.

43. Sawaya H, Sebag IA, Plana JC, Januzzi JL, Ky B, Tan TC, et al. Assessment of echocardiography and biomarkers for the extended prediction of cardiotoxicity in patients treated with anthracyclines, taxanes, and trastuzumab. Circ Cardiovasc Imaging 2012;5:596-603.

44. Kocabay G, Muraru D, Peluso D, Cucchini U, Mihaila S, Padayattil-Jose S, et al. Normal left ventricular mechanics by two-dimensional speckle-tracking echocardiography. Reference values in healthy adults. Rev Esp Cardiol (Engl Ed) 2014;67:651-8.

45. Takigiku K, Takeuchi M, Izumi C, Yuda S, Sakata K, Ohte $\mathrm{N}$, et al. Normal range of left ventricular 2-dimensional strain: Japanese ultrasound speckle tracking of the left ventricle (JUSTICE) study. Circ J 2012;76:2623-32. 